Signal \& Image Processing : An International Journal (SIPIJ) Vol.3, No.5, October 2012

\title{
HIGHLY EFFECTIVE AND EFFICIENT SPECTRAL ANALYSIS THROUGH MULTIRATE DIGITAL FILLTER BANK
}

\author{
Ganekanti Hemanja ${ }^{1}$, Dr. K. Satya Prasad ${ }^{2}$ and P. Venkata Subbaiah ${ }^{3}$ \\ ${ }^{1}$ Research scholar, JNTU, Kakinada, E.G. Dist., A.P., India \\ ganekantihemanj@yahoo.com \\ ${ }^{2}$ Professor in ECE Dept. and Rector, JNTU, Kakinada, E.G. Dist., A.P., India \\ Prasad_kodati@yahoo.co.in \\ ${ }^{3}$ Professor in ECE Dept. and Principal, ASIST, Paritala, Krishna Dist., A.P., India. \\ Pvs_ece2000@yahoo.co.in
}

\begin{abstract}
Digital filtering is considered to be an important operation in reconstruction and visualization of information, besides amounting to increase in computational efficiency. The Finite Impulse Response based digital filter bank is better responsive in respect of above specified advantages. In this paper, we propose a novel approach in digital bandpass filter bank through Modified Kaiser window based Multirate technique as specified in (1)(2). A remarkable spectral output is achieved by way of increase in peak response, better selectivity, more stopband attenuation, better frequency response and computational efficiency as compared to the existing methods(3)(4)(5). The simulation results are exhibited on account of satisfactory performance and comparison is drawn to verify the advantages in the proposed method. This type of filter bank is more suitable in typical hearing aid applications in order to arrive significant merits for improving quality of output.
\end{abstract}

\section{KEYWORDS}

Multirate processing, Heterodyning, Bandpass filtering, Modified Kaiser Window, Spectral Output, Computational Efficiency.

\section{INTRODUCTION}

Many applications require effective detection of signals, mainly in terms of amplitude and frequency components so that it becomes easier in processing of signals and implementation of hardware at the succeeding stages, thus enable to achieve a most significant output.In this connection, the role of bandpass filter is utmost form of concern for selection of desired frequency and quality of response, in addition, it be computationally efficient. To cover these aspects, this paper emerges a novel method in spectral analysis to best suit among various applications. There is a scope of possible enhancement in respect of selectivity, peak response, stopband attenuation and quality output as referred in these results clarified by authors (3)(4)(5). In addition, less side lobes and prescribed vanishing moments are achievable for better suitable in Multicarrier applications and deriving better gain to work well with image coding when compared with existing methods as clarified by the authors (11) and (12) respectively. Hence, our proposed method of bandpass filter bank is suggested to overcome the specified disadvantages

DOI : $10.5121 /$ sipij.2012.3510 
Signal \& Image Processing : An International Journal (SIPIJ) Vol.3, No.5, October 2012

among these methods, depicted for various applications. The FIR band pass filter is considered because it has significant number of advantages including precise control over the phase response so as to facilitate for better signal reconstruction and thus adopted for achieving more effectiveness in respect of the advantages, as specified. Each filter stage is designed based on 'Modified Kaiser window' as this method is effectively implemented with a novel approach in Multirate processing technique. This method has been drawn with enhanced characteristics in respect of passband and stopband ripple and quality output when compared with methods (6)(7). The actual part of work is done with a new technique in Multirate digital signal processing, in which, the Input signal generation and filter bank design are implemented at much reduced sampling frequency.This possibility is arrived through heterodyning operation performed on input, generated at band of interest. This process converts the frequency band of input signal to lowest possible frequency band, that is, from ' 0 ' Hz.. This method of technique has been arrived with a great reduction in computational complexity because of great reduction in number of input samples and filter order along with the specified advantages. The proposed method is well explained in this paper with the help of analytic equations. The simulation results and performance characteristics are arrived to verify with the facts. This method is thoroughly checked at lower frequencies because of quality assurance, implemented even at higher frequencies and so chosen the input signal to be 'Cosine function' as this function represents the real time signals in most of applications.

\section{ANALYSIS OF METHOD AND RELATED EQUATIONS}

\subsection{Bandpass filter design}

The Modified method of approach in filter design is arrived through partial modification of specified parameters in the existing Kaiser window method (8).

The frequency response of bandpass filter is given as

$$
h(z)=\left\{\begin{array}{l}
1 \ldots \ldots . . \text { for } \ldots f_{p 1} \leq|f| \leq f_{p 2} \\
0 \ldots \ldots . \text { for } \ldots .|f|\left\langle f_{p 1} \ldots \text { and } \ldots|f|\right\rangle f_{p 2}
\end{array}\right.
$$

Where $\mathrm{fp}_{1}$ is lower pass band frequency and $\mathrm{fp}_{2}$ is higher pass band frequency .

The desired unit sample response is given by $h_{d}(n)$.

$$
\begin{aligned}
h_{d}(n) & \left.=\frac{1}{n \pi}\left[\sin \left(\frac{2 \pi n f_{c 2}}{F}\right)-\sin \left(\frac{2 \pi n f_{c 1}}{F}\right)\right]--- \text { for } \ldots n\right\rangle 0 \\
& =\frac{2}{F}\left(f_{c 2}-f_{c 1}\right)--- \text { for } \ldots n=0
\end{aligned}
$$

Where

$\mathrm{f}_{\mathrm{c} 1}=\mathrm{f}_{\mathrm{p} 1}-(\mathrm{df} / 2), \mathrm{f}_{\mathrm{c} 2}=\mathrm{f}_{\mathrm{p} 2}+(\mathrm{df} / 2)$

df $2=f_{p 1}-f_{s 1}$, df $3=f_{\mathrm{s} 2}-f_{p 2}$

Where $\mathrm{df}=\min \{\mathrm{df} 2, \mathrm{df} 3\}$,

$\mathrm{F}=$ Sampling frequency

$\mathrm{f}_{\mathrm{s} 1}=$ Lower stop band frequency

$\mathrm{f}_{\mathrm{s} 2}=$ Upper stop band frequency 
Signal \& Image Processing : An International Journal (SIPIJ) Vol.3, No.5, October 2012

$\mathrm{n}=$ integer

$\mathrm{N}^{\prime}=$ Order of the filter

The frequency response of the $h_{d}(n)$ is given by $h(z)$.

$h(z)=z^{-\left(N^{\prime}-1\right) / 2}\left[h_{d}(0)+\sum_{n=1}^{\left(N^{\prime}-1\right)} 2 h_{d}(n) \cos (2 \pi f n T)\right]$

Where $h_{d}(0)+\sum_{n=1}^{\left(N^{\prime}-1\right)} 2 h_{d}(n) \cos (2 \pi f n T)$

represents the magnitude response equation, where $\mathrm{T}=1 / \mathrm{F}$.

\subsection{Design of Window}

The basic Kaiser window function

$$
a_{k}(n)=\left\{\begin{array}{l}
\frac{I_{o}(B)}{I_{o}(A)}---- \text { for } \cdots n \leq(N-1) / 2 \\
0------- \text { Otherwise }
\end{array}\right.
$$

Where ' $\mathrm{A}$ ' is an independent variable empirically determined by Kaiser.

$$
\begin{aligned}
& B=A\left(1-\left(\frac{2 n}{\left(N^{\prime}-1\right)}\right)^{2}\right)^{0.5} \\
& I_{o}(x)=1+\frac{\left(0.5 x^{2}\right)}{(1 !)^{2}}+\frac{\left(0.5 x^{2}\right)^{2}}{(2 !)^{2}}+------
\end{aligned}
$$

This series converges rapidly and can be computed up to 25 terms to get the desired accuracy. While considering the bandpass specifications, where the passband ripple (Ap) and minimum stopband attenuation (As) in decibels are given by

$$
\begin{aligned}
& A p=20 \log _{10} \frac{(1+d p))}{(1-d p)} \\
& A s=-20 \log _{10}(d s)
\end{aligned}
$$

The 'ds' and 'dp' can be determined as

$$
\begin{aligned}
& d s=10^{(-0.05 A s)} \\
& d p=\frac{\left(10^{A p}-1\right)}{\left(10^{0.05 A p}+1\right)}
\end{aligned}
$$

$\mathrm{dp}=\min (\mathrm{dp}, \mathrm{ds})$

The actual stopband attenuation is arrived to be, $A s=20 \log _{10}(d p)$

The value of ' $\mathrm{A}$ ' is determined from the empirical design equation 
Signal \& Image Processing : An International Journal (SIPIJ) Vol.3, No.5, October 2012

$$
\begin{aligned}
& A=0 \text {----for As } \leq 21 \\
& \quad \text { or } \\
& A=0.5942(\text { As-21) } 0.4+0.7986(\text { As-20) for } 21 \leq A s \leq 50 \\
& \quad \text { or } \\
& A=0.1102(\text { As-8.7) for As }>50
\end{aligned}
$$

A parameter ' $\mathrm{D}$ ' is determined from the empirical design equation

$$
D=\left\{\begin{array}{l}
0.9222 \ldots \ldots \ldots \ldots \ldots \text { for } \cdots A s \leq 21 \\
\left.\left(\frac{A s-7.95}{13.95}\right) \ldots \ldots . . \text { for } \cdots \text { As }\right\rangle 21
\end{array}\right.
$$

The filter order for the lowest odd value of 'N', calculated to be

$$
\mathrm{N}^{\prime} \geq \frac{\left(F^{*} D\right)}{d f}+1
$$

The order of the filter increases with increase in the sampling frequency or decrease in the transition width.

Finally, the unit sample response of the FIR bandpass filter is determined as $h(n)=a_{k}(n) h_{d}(n)$

Where $a_{k}(n)$ and $h_{d}(n)$ are window coefficients and desired unit sample response respectively. The frequency response and the output response of the filter bank are simulated according to Modified Kaiser window approach, as shown in Figure 1 and Figure 2 respectively. It is observed that a better spectral response with improvement in passband and stopband ripple and quality of output are attained as compared to the existing methods of reference $(6)(7)(8)$. This novel approach of filter bank design has brought attractive advantages in the proposed method of filter bank response, which follows.

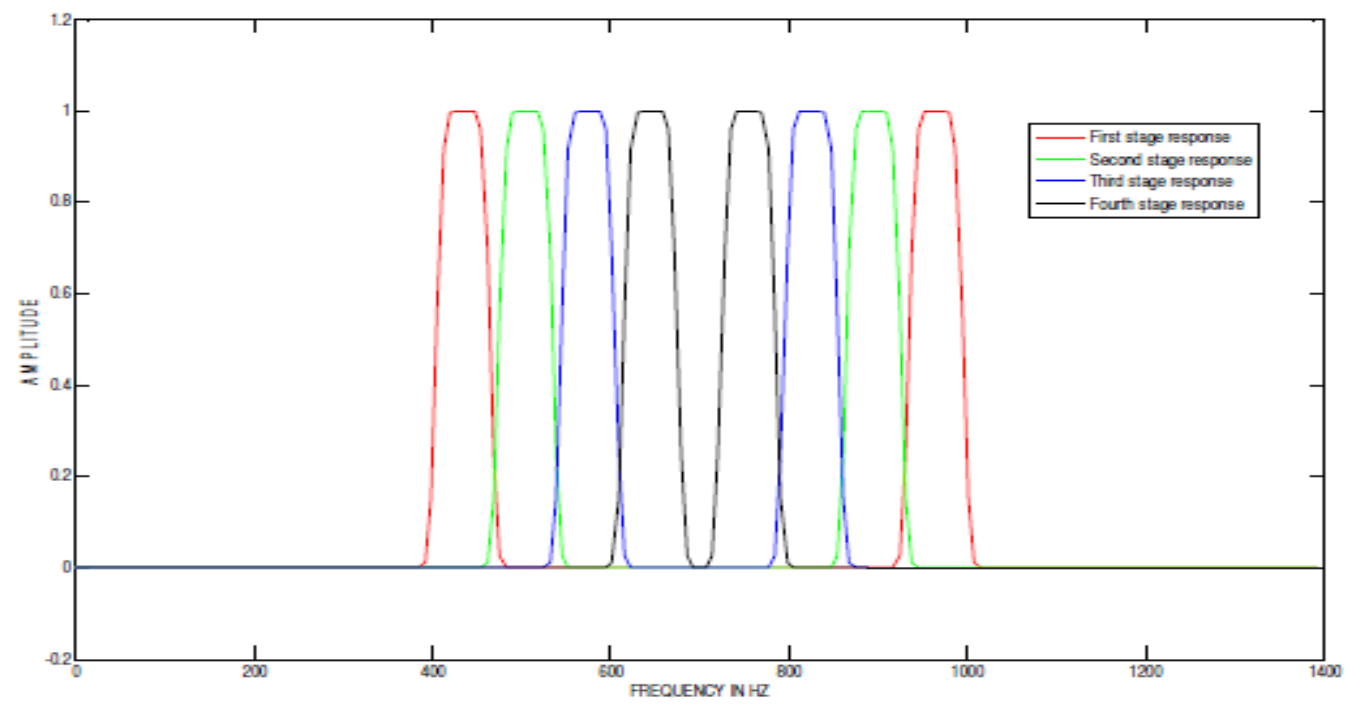

Figure 1. Modified Kaiser window based frequency response of bandpass filter bank 
Signal \& Image Processing : An International Journal (SIPIJ) Vol.3, No.5, October 2012

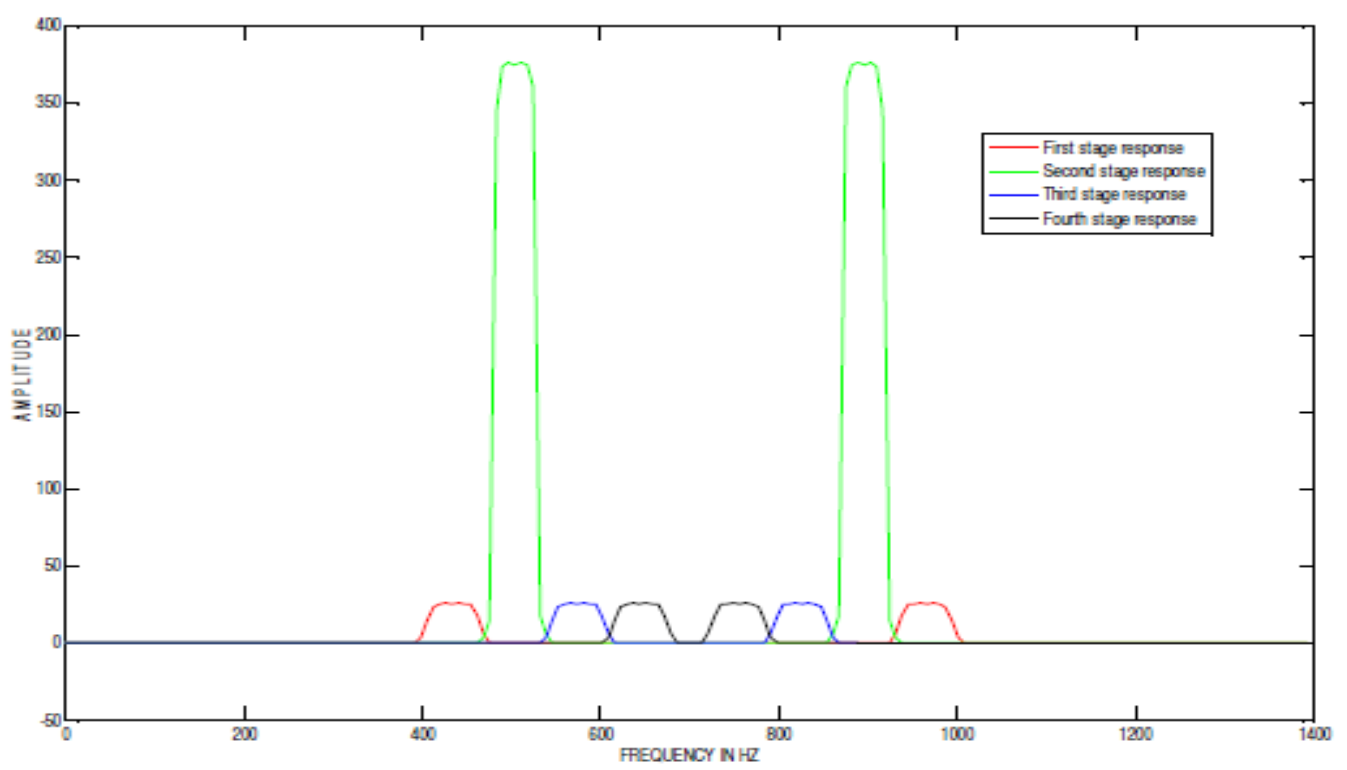

Figure 2. Modified Kaiser window based output response of bandpass filter bank for the input signal band of frequencies from $480 \mathrm{~Hz}$ to $530 \mathrm{~Hz}$ (With existing method)

\section{FILTER BANK RESPONSE WITH NEW TECHNIQUE IN MULTIRATE PROCESSING}

The proposed method is a new technique in Multirate processing, that is appended to filter bank which causes better selectivity, more peak response, better stopband attenuation in addition to much improvement in spectral response as compared to existing methods (3)(4)(5). More over, the specified advantages in the proposed method are achieved at minimum number of computations that result an optimal time in processing. In this technique, each sample is multiplied by a value, derived by cosine function which is related to starting frequency of band of interest and starting frequency of the modified input signal. The novel method is to further modify the sample values of input in such a way that the shifted input sample values are added with sample values of modified input function at the respective intervals of time in order to derive the 'Net input samples' at reduced sampling frequency. The samples of modified input function are taken at same intervals with negative sample values and having the magnitude, $(1 / 14)^{\text {th }}$ of original input, taken at stopband frequencies. The Net input samples are significantly processed as mentioned below, so that the specified advantages in the passband frequencies are met in the proposed method. Further, these Net input samples are right shifted by 'N2' samples as determined by number of frequency points of output response, as shown in the figure 3 , and the number of frequency points are taken as $1 / 4^{\text {th }}$ of sampling frequency in order to achieve better smooth response in the frequency domain to be obtained at output of filter bank as shown in Figure 4. 
Signal \& Image Processing : An International Journal (SIPIJ) Vol.3, No.5, October 2012

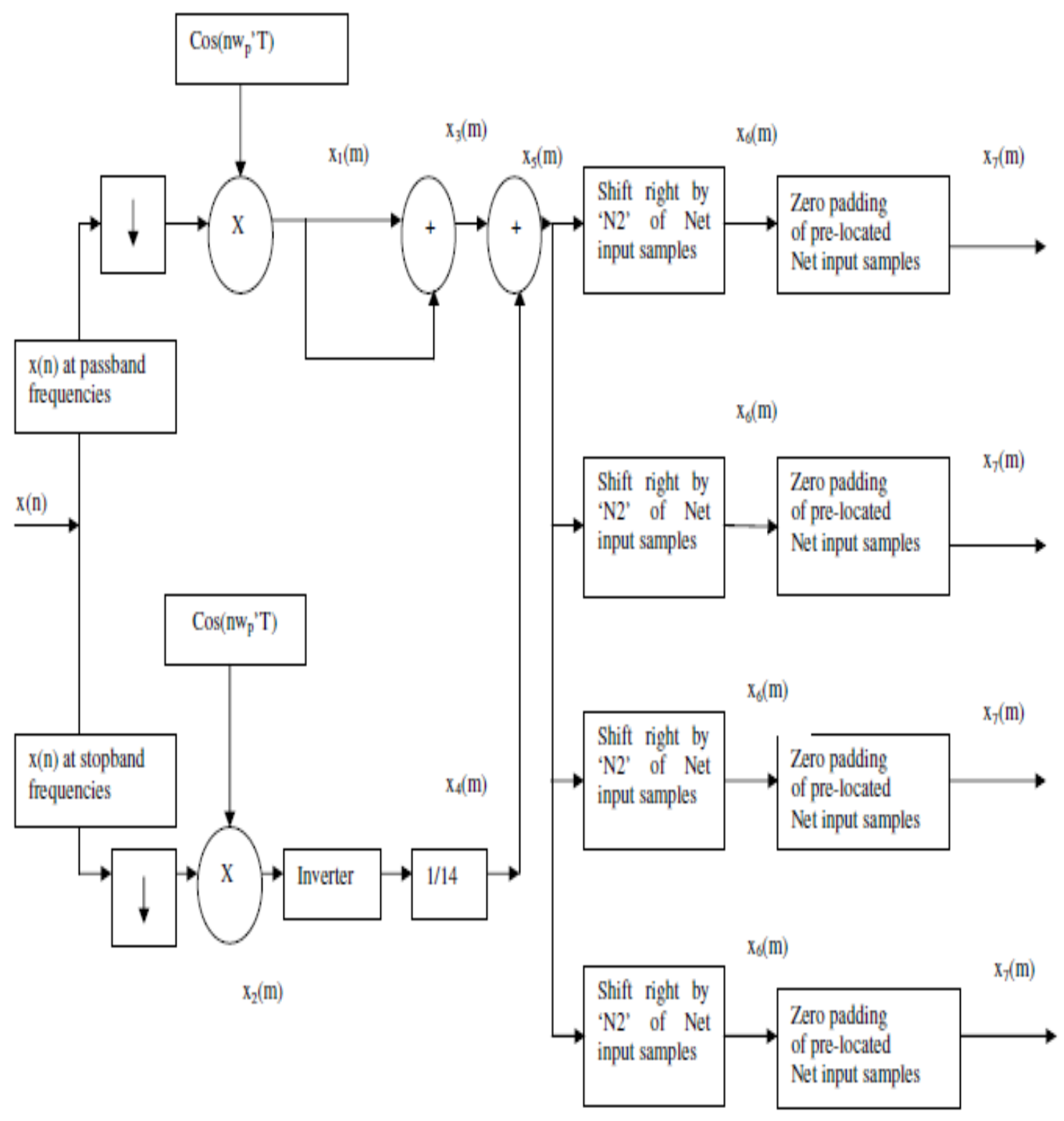

Figure 3. Block diagram for generation of last form of Net input samples before applying to bandpass filter bank of proposed method 
Signal \& Image Processing : An International Journal (SIPIJ) Vol.3, No.5, October 2012

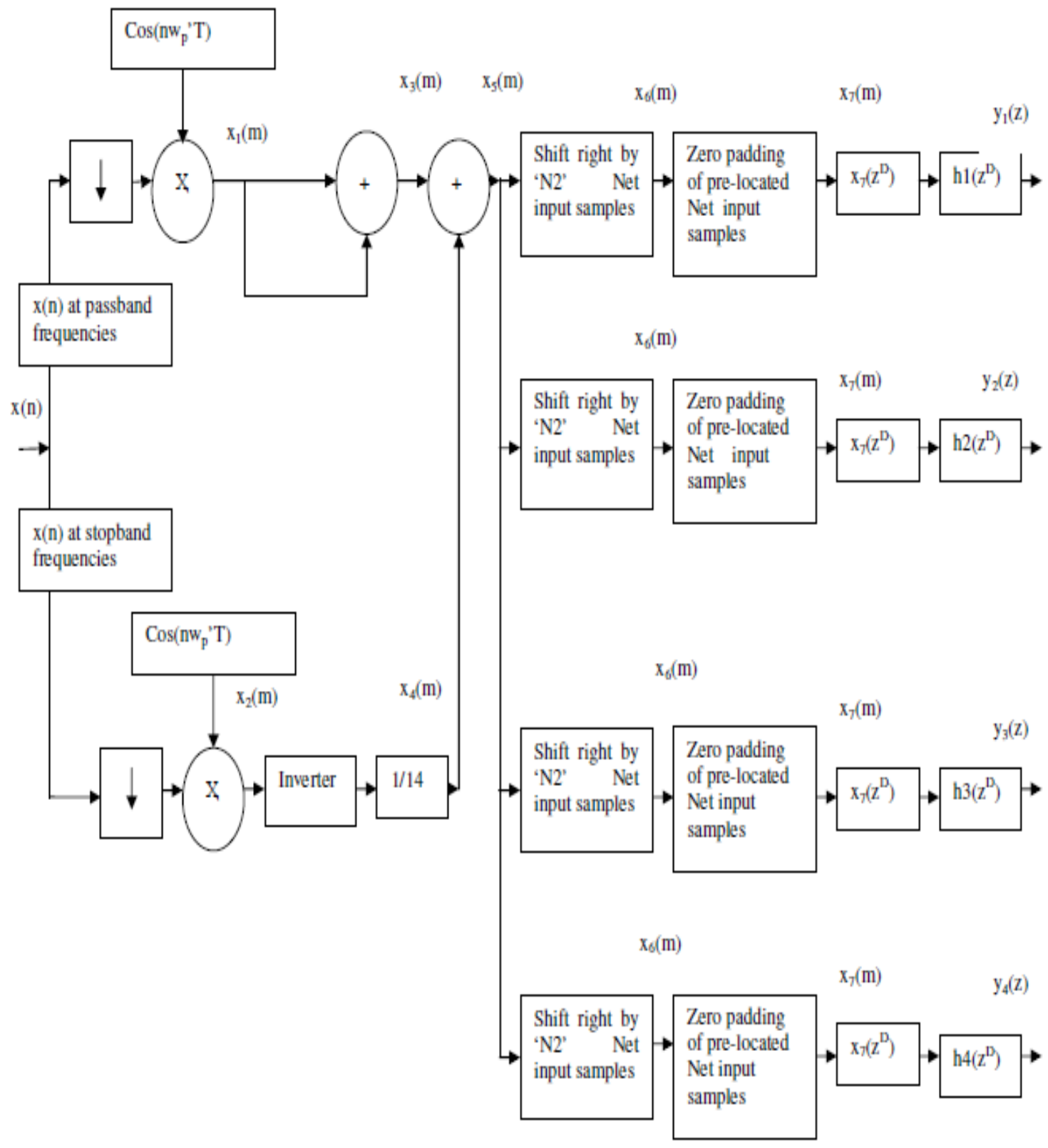

Figure 4. Block diagram for proposed method of filter bank frequency domain output

The pre-located Net input samples are zero padded. This technique of time domain shifting and zero padding at selected points of input as mentioned in this novel approach has created a new dimension to arrive significantly a quality output. Now, these modified Net input samples are taken as input to the individual stage of bandpass filter bank and each bandpass filter is designed to meet the desired specifications as shown in Table 1 . 
Signal \& Image Processing : An International Journal (SIPIJ) Vol.3, No.5, October 2012

Table 1. Passband and stopband frequencies of proposed method of filter bank

\begin{tabular}{|c|c|c|c|c|}
\hline & $\begin{array}{c}\text { Lower stopband } \\
\text { frequency } \\
\mathrm{f}_{\mathrm{s} 1} \\
(\mathrm{~Hz})\end{array}$ & $\begin{array}{c}\text { Lower passband } \\
\text { frequency } \\
\mathrm{f}_{\mathrm{p} 1} \\
(\mathrm{~Hz})\end{array}$ & $\begin{array}{c}\text { Upper passband } \\
\text { frequency } \\
\mathrm{f}_{\mathrm{p} 2} \\
(\mathrm{~Hz})\end{array}$ & $\begin{array}{c}\text { Upper stopband } \\
\text { frequency } \\
\left(\mathrm{f}_{\mathrm{s} 2}\right.\end{array}$ \\
\hline Stage 1 & 0 & 10 & 60 & 70 \\
\hline Stage 2 & 70 & 80 & 130 & 140 \\
\hline Stage 3 & 140 & 150 & 200 & 210 \\
\hline Stage 4 & 210 & 220 & 270 & 280 \\
\hline
\end{tabular}

From Figure 1, the signal conversions at various points upon input signal can be considered in the form as mentioned below.

$\mathrm{x}_{1}(\mathrm{~m})=\mathrm{x}(\mathrm{n})\left(\cos \left(\mathrm{nw}_{\mathrm{p}}{ }^{\prime} \mathrm{T}\right)\right)$

$\mathrm{x}_{2}(\mathrm{~m})=\mathrm{x}(\mathrm{n})\left(\cos \left(\mathrm{nw}_{\mathrm{p}}{ }^{\prime} \mathrm{T}\right)\right)$

Where ' $\mathrm{w}_{\mathrm{p}}$ "' is the starting frequency of input signal band in $\mathrm{rad} / \mathrm{sec}$. and $\mathrm{x}(\mathrm{n})$ is the input signal, where $n=0,1,2,------$ (N1-1).

The samples of $x_{1}(m)$ and $x_{2}(m)$ are obtained at the decimated sampling frequency such that the decimation factor, $\mathrm{D}=\mathrm{F} / \mathrm{F}$ ', where ' $\mathrm{F}$ ' is the decimated sampling frequency.

Let $\mathrm{x}(\mathrm{nT})$ be the input signal and its number of input samples be ' $\mathrm{N} 1$ '.

The decimated output of original input signal can be extracted by using the Interpolation formula as given below.

$\mathrm{x}_{1}(\mathrm{mT} \mathrm{y})=\sum_{n=0}^{(N 1-1)} x(n T) g(m T y-n T)$

Where ' $\mathrm{T}$ ' is the original sampling period and ' $\mathrm{Ty}$ ' is the sampling period of decimated output. The ' $n$ ' and ' $m$ ' are the sample numbers of original and modified input signals respectively and each of individual sample is extracted as per sampling period ' $\mathrm{T}$ ' and 'Ty' respectively .

Where $\mathrm{g}(\mathrm{t})$ is given as

$$
g(t)=\frac{\sin (\pi t / T)}{(\pi t / T)} \leftrightarrow G(F 1)=\left\{\begin{array}{l}
T, \cdots|F 1| \leq F / 2 \\
0, \cdots \text { otherwise }
\end{array}\right.
$$

The equation (3.1) can be written as below for suitable representation in different form as given in equation (3.2).

$\mathrm{x}_{1}(\mathrm{mT} T)=\sum_{n=0}^{(N 1-1)} x(n T) g\left(T\left(\frac{m T y}{T}-n\right)\right)$ 
Signal \& Image Processing : An International Journal (SIPIJ) Vol.3, No.5, October 2012

The term $\frac{m T y}{T}$ can be decomposed into an integer part ' $\mathrm{k}_{\mathrm{m}}$ ' and a fractional part $\Delta \mathrm{m}, 0 \leq \Delta \mathrm{m} \leq 1$, as

$\frac{m T y}{T}=\mathrm{k}_{\mathrm{m}}+\Delta \mathrm{m}$

Where $\left.\mathrm{k}_{\mathrm{m}}=\mathrm{L} \frac{m T y}{T}\right\lrcorner$

and $\left.\Delta \mathrm{m}=\frac{m T y}{T}-\mathrm{L} \frac{m T y}{T}\right\lrcorner$

The symbol $\left.L_{a}\right\rfloor$ denotes the largest integer contained in 'a'. The quantity ' $\Delta \mathrm{m}$ ' specifies the position of the current sample within the sample period 'T'. Substituting Equation (3.3) into Equation (3.2), it is obtained as

$\mathrm{x}_{1}(\mathrm{mT} \mathrm{y})=\sum_{n=0}^{(N 1-1)} x(n T) g\left(\left(k_{m}+\Delta m-n\right) T\right)$

Equation (3.4) provides the fundamental equation for the discrete implementation of sampling rate conversion of $\mathrm{x}(\mathrm{n})$ at passband frequencies.

$\mathrm{x}_{2}(\mathrm{mT} \mathrm{y})=\sum_{n=0}^{(N 1-1)} x(n T) g\left(\left(k_{m}+\Delta m-n\right) T\right)$

In similar steps, Equation (3.5) provides the fundamental equation for the discrete implementation of sampling rate conversion of $\mathrm{x}(\mathrm{n})$ at stopband frequencies.

$\mathrm{x}_{3}(\mathrm{~m})=\mathrm{x}_{1}(\mathrm{~m})+\mathrm{x}_{1}(\mathrm{~m})$

$\mathrm{x}_{4}(\mathrm{~m})=\left(-\mathrm{x}_{2}(\mathrm{~m})(1 / 14)\right)$

The sample values of $\mathrm{x}_{4}(\mathrm{~m})$ are taken at stopband frequencies at the varied frequency point ' $\mathrm{f}$ '.

$\mathrm{x}_{5}(\mathrm{~m})=\mathrm{x}_{3}(\mathrm{~m})+\mathrm{x}_{4}(\mathrm{~m})$

The $\mathrm{x}_{5}(\mathrm{~m})$ is the Net input signal and for all above equations the value ' $\mathrm{m}$ ' is taken at

$0,1,2,3,-------(\mathrm{M}-1)$.

$\mathrm{x}_{6}(\mathrm{~m}+\mathrm{N} 2)=\mathrm{x}_{5}(\mathrm{~m})$, where $\mathrm{m}=0,1,2,-----------(\mathrm{M}-1)$

Where ' $M$ ' are number of input samples as corresponding to the decimated sampling frequency, 'F'' and 'N2' are number of shifted samples as earmarked by number of frequency points.

$\mathrm{x}_{6}(\mathrm{~m})=0 \quad$ for $\mathrm{m}=0,1,2,---(\mathrm{N} 2-1)$

$\mathrm{x}_{7}(\mathrm{~m})=\mathrm{x}_{6}(\mathrm{~m})$ for $\mathrm{m}=0,1,2,---(\mathrm{N} 2+\mathrm{M}-1)$,

Finally the frequency response of $\mathrm{x}_{7}(\mathrm{~m})$ is carried out at decimated sampling frequency as given by the relation 
$\mathrm{x}_{7}\left(\mathrm{z}^{\mathrm{D}}\right)=\sum_{n=0}^{(N 2+N 1-1)} x_{7}(n) e^{(-j 2 \pi f n T y)}$

Where

$\mathrm{Ty}=1 / \mathrm{F}^{\prime}$ and $\mathrm{z}^{\mathrm{D}}=\mathrm{e}^{(-j 2 \pi f T y)}$,

' $F$ ' $=$ decimated sampling frequency so that Decimation factor ' $D$ ' $=F / F$ ',

' $\mathrm{f}$ ' = A frequency point at which the amplitude response is deduced. Depicting the subsequent procedure, Figure 2 shows the structure of frequency domain bandpass filter bank with reference to Figure 1. As in Figure 2, the frequency response of each bandpass filter is taken $\operatorname{as}_{1}\left(z^{D}\right)$, $\mathrm{h}_{2}\left(\mathrm{z}^{\mathrm{D}}\right) \ldots . \mathrm{h}_{\mathrm{n}}\left(\mathrm{z}^{\mathrm{D}}\right)$ and the output response of each band pass filter in the filter bank is arrived such that

$\mathrm{y}_{1}(\mathrm{z})=\mathrm{x}_{7}\left(\mathrm{z}^{\mathrm{D}}\right)\left(\mathrm{h}_{1}\left(\mathrm{z}^{\mathrm{D}}\right)\right)$

$\mathrm{y}_{2}(\mathrm{z})=\mathrm{x}_{7}\left(\mathrm{z}^{\mathrm{D}}\right)\left(\mathrm{h}_{2}\left(\mathrm{z}^{\mathrm{D}}\right)\right)$

.........................

n.....................

$\mathrm{y}_{\mathrm{n}}(\mathrm{z})=\mathrm{x}_{7}\left(\mathrm{z}^{\mathrm{D}}\right)\left(\mathrm{h}_{\mathrm{n}}\left(\mathrm{z}^{\mathrm{D}}\right)\right)$

\section{RESULTS AND DISCUSSION}

The proposed method of spectral analysis is done, as an example, for four input frequency bands comprising four bandpass filter stages within frequency band of interest between $400 \mathrm{~Hz}$ and 680 Hz. The methodology and advantages have been explained in detail by the following example. Assuming the input signal to be in the frequency range between $410 \mathrm{~Hz}$ and $670 \mathrm{~Hz}$ for which the sampling frequency can be taken as $2 * 700=1400 \mathrm{~Hz}$. The sampling frequency is reduced to 800 $\mathrm{Hz}$ by a decimation factor ' $\mathrm{D}$ ' such that the value ' $\mathrm{D}$ ' can be taken as $(1400 / 800)$. The decimated sampling frequency is so arrived that result in no 'Aliasing' for the frequency modified input signal. The filter bank is designed between $0 \mathrm{~Hz}$ and $280 \mathrm{~Hz}$ corresponding to the input signal band between $410 \mathrm{~Hz}$ and $670 \mathrm{~Hz}$ as the original frequency band is shifted correspondingly between $10 \mathrm{~Hz}$ and $270 \mathrm{~Hz}$. Among four stages of filter bank, each stage has got a bandwidth of $50 \mathrm{~Hz}$. The shifted pass band and stopband frequencies of these stages are as shown in Table 1 .

Initially the specifications of pass band ripple and stopband attenuation are assumed as $0.5 \&$ $35 \mathrm{~dB}$ respectively. As per the design constraints, these specifications are achieved with better values, when compared with the simulation results of the methods (3)(4)(5) and rather designed with Modified Kaiser window as shown from Table 2 to Table 5, as a point of example, where the input frequency band is selected between $480 \mathrm{~Hz}$ and $530 \mathrm{~Hz}$. The similar advantages are arrived for other input band of frequencies, as shown from these results. 
Signal \& Image Processing : An International Journal (SIPIJ) Vol.3, No.5, October 2012

Table 2. Amplitude response of the existing method of filter bank for the input signal band of frequencies, taken from $480 \mathrm{~Hz}$ to $530 \mathrm{~Hz}$ (Using Modified Kaiser window).

\begin{tabular}{|c|c|c|}
\hline S.NO. & $\begin{array}{c}\text { Input } \\
\text { frequency } \\
\text { band } \\
(\mathrm{Hz})\end{array}$ & $\begin{array}{c}\text { Normalised } \\
\text { amplitude }\end{array}$ \\
\hline 1 & $410-460$ & 0.104 \\
\hline 2 & $480-530$ & 1 \\
\hline 3 & $550-600$ & 0.104 \\
\hline 4 & $620-670$ & 0.104 \\
\hline
\end{tabular}

Table 3. Values of filter parameters as per simulation results of existing method of filter bank for the input signal band of frequencies from $480 \mathrm{~Hz}$ to $530 \mathrm{~Hz}$ (Using Modified Kaiser window).

\begin{tabular}{|c|c|c|c|c|c|}
\hline S.No. & $\begin{array}{l}\text { Input } \\
\text { frequency } \\
\text { band } \\
(\mathrm{Hz})\end{array}$ & $\begin{array}{l}\text { Assumed } \\
\text { passband } \\
\text { and } \\
\text { stopband } \\
\text { frequencies } \\
\text { (Hz) }\end{array}$ & $\begin{array}{l}\text { Simulated results of } \\
\text { passband and } \\
\text { stopband frequencies } \\
(\mathrm{Hz})\end{array}$ & $\begin{array}{l}\text { Filter } \\
\text { order }\end{array}$ & $\begin{array}{c}\text { Passband and } \\
\text { stopband attermation } \\
\text { of output response } \\
\text { (dB) } \\
\text { (As Per Figure 2) }\end{array}$ \\
\hline 1 & $410-460$ & $\begin{array}{l}f_{31}=400 \\
f_{p 1}=410 \\
f_{p 2}=460 \\
f_{22}=470\end{array}$ & $\begin{array}{l}f_{51}=400 \\
f_{p 1}=410 \\
f_{02}=460 \\
f_{22}=470\end{array}$ & 283 & 19.66 \\
\hline 2 & $480-530$ & $\begin{array}{l}f_{21}=470 \\
f_{p 1}=480 \\
f_{p 2}=530 \\
f_{s_{2}}=540\end{array}$ & $\begin{array}{l}f_{51}=470 \\
f_{p 1}=480 \\
f_{p 2}=530 \\
f_{f_{2}}=540\end{array}$ & 283 & 0 \\
\hline 3 & $550-600$ & $\begin{array}{l}f_{51}=540 \\
f_{p 1}=550 \\
f_{p 2}=600 \\
f_{p_{2}}=610\end{array}$ & $\begin{array}{l}f_{51}=540 \\
f_{p 1}=550 \\
f_{02}=600 \\
f_{f_{2}}=610\end{array}$ & 283 & 19.66 \\
\hline 4 & $620-670$ & $\begin{array}{l}f_{31}=610 \\
f_{p 1}=620 \\
f_{p 2}=670 \\
f_{22}=680\end{array}$ & $\begin{array}{l}f_{51}=610 \\
f_{p 1}=620 \\
f_{02}=670 \\
f_{s_{2}}=680\end{array}$ & 283 & 19.66 \\
\hline
\end{tabular}


Signal \& Image Processing : An International Journal (SIPIJ) Vol.3, No.5, October 2012

Table 4. Amplitude response of proposed method of filter bank for the input signal band of frequencies from $410 \mathrm{~Hz}$ to $460 \mathrm{~Hz}$.

\begin{tabular}{|c|c|c|c|}
\hline S.No. & $\begin{array}{c}\text { Assumed } \\
\text { input } \\
\text { frequency } \\
\text { band } \\
(\mathrm{Hz})\end{array}$ & $\begin{array}{c}\text { Translated } \\
\text { band of } \\
\text { input } \\
\text { frequencies } \\
(\mathrm{Hz})\end{array}$ & $\begin{array}{c}\text { Normalized } \\
\text { amplitude at passband } \\
\text { and } \\
\text { stopband } \\
\text { frequencies } \\
\text { (As per Figure 6) }\end{array}$ \\
\hline 1 & $410-460$ & $10-60$ & 1 \\
\hline 2 & $480-530$ & $80-130$ & 0.0001 \\
\hline 3 & $550-600$ & $150-200$ & 0.0001 \\
\hline 4 & $620-670$ & $220-270$ & 0.0001 \\
\hline
\end{tabular}

Table 5. Values of filter parameters as per the simulation results of proposed method of filter bank for the input signal band of frequencies from $410 \mathrm{~Hz}$ to $460 \mathrm{~Hz}$.

\begin{tabular}{|c|c|c|c|c|c|c|}
\hline S.No. & $\begin{array}{c}\text { Input } \\
\text { frequency } \\
\text { band } \\
(\mathrm{Hz})\end{array}$ & $\begin{array}{c}\text { Assumed } \\
\text { passband \& } \\
\text { stopband } \\
\text { frequencies } \\
(\mathrm{Hz})\end{array}$ & $\begin{array}{c}\text { Translated } \\
\text { band of input } \\
\text { frequencies } \\
(\mathrm{Hz})\end{array}$ & $\begin{array}{l}\text { Simulated } \\
\text { results of } \\
\text { passband } \\
\text { and } \\
\text { stopband } \\
\text { frequencie } \\
\text { s } \\
(\mathrm{Hz})\end{array}$ & $\begin{array}{c}\text { Filter } \\
\text { order } \\
\& \\
\text { passban } \\
\text { d and } \\
\text { stopban } \\
\text { d ripple } \\
(\mathrm{dB})\end{array}$ & $\begin{array}{l}\text { Passband } \\
\text { and } \\
\text { stopband } \\
\text { attenuation } \\
\text { of } \\
\text { output } \\
\text { response } \\
\text { (dB) } \\
\text { (As per } \\
\text { Figure 6) }\end{array}$ \\
\hline 1 & $410-460$ & $\begin{array}{l}\mathrm{f}_{\mathrm{s} 1}=400 \\
\mathrm{f}_{\mathrm{p} 1}=410 \\
\mathrm{f}_{\mathrm{p} 2}=460 \\
\mathrm{f}_{\mathrm{s} 2}=470\end{array}$ & $\begin{aligned} \mathrm{f}_{\mathrm{s} 1} & =0 \\
\mathrm{f}_{\mathrm{p} 1} & =10 \\
\mathrm{f}_{\mathrm{p} 2} & =60 \\
\mathrm{f}_{\mathrm{s} 2} & =70\end{aligned}$ & $\begin{aligned} \mathrm{f}_{\mathrm{s} 1}=0 \\
\mathrm{f}_{\mathrm{p} 1}=10 \\
\mathrm{f}_{\mathrm{p} 2}=60 \\
\mathrm{f}_{\mathrm{s} 2}=70\end{aligned}$ & $163 \& 0$ & 0 \\
\hline 2 & $480-530$ & $\begin{array}{l}\mathrm{f}_{\mathrm{s} 1}=470 \\
\mathrm{f}_{\mathrm{p} 1}=480 \\
\mathrm{f}_{\mathrm{p} 2}=530 \\
\mathrm{f}_{\mathrm{s} 2}=540\end{array}$ & $\begin{array}{r}\mathrm{f}_{\mathrm{s} 1}=70 \\
\mathrm{f}_{\mathrm{p} 1}=80 \\
\mathrm{f}_{\mathrm{p} 2}=130 \\
\mathrm{f}_{\mathrm{s} 2}=140\end{array}$ & $\begin{array}{l}\mathrm{f}_{\mathrm{s} 1}=70 \\
\mathrm{f}_{\mathrm{p} 1}= \\
80 \\
\mathrm{f}_{\mathrm{p} 2}=130 \\
\mathrm{f}_{\mathrm{s} 2}=140\end{array}$ & $163 \& 0$ & 80 \\
\hline 3 & $550-600$ & $\begin{array}{l}\mathrm{f}_{\mathrm{s} 1}=540 \\
\mathrm{f}_{\mathrm{p} 1}=550 \\
\mathrm{f}_{\mathrm{p} 2}=600 \\
\mathrm{f}_{\mathrm{s} 2}=610\end{array}$ & $\begin{array}{l}\mathrm{f}_{\mathrm{s} 1}=140 \\
\mathrm{f}_{\mathrm{p} 1}=150 \\
\mathrm{f}_{\mathrm{p} 2}=200 \\
\mathrm{f}_{\mathrm{s} 2}=210\end{array}$ & $\begin{array}{l}\mathrm{f}_{\mathrm{s} 1}=140 \\
\mathrm{f}_{\mathrm{p} 1}=150 \\
\mathrm{f}_{\mathrm{p} 2}=200 \\
\mathrm{f}_{\mathrm{s} 2}=210\end{array}$ & $163 \& 0$ & 80 \\
\hline
\end{tabular}


Signal \& Image Processing : An International Journal (SIPIJ) Vol.3, No.5, October 2012

\begin{tabular}{|c|c|c|c|c|c|c|}
\hline 4 & $620-670$ & $\begin{array}{l}\mathrm{f}_{\mathrm{s} 1}=610 \\
\mathrm{f}_{\mathrm{p} 1}=620 \\
\mathrm{f}_{\mathrm{p} 2}=670 \\
\mathrm{f}_{\mathrm{s} 2}=680\end{array}$ & $\begin{array}{l}\mathrm{f}_{\mathrm{s} 1}=210 \\
\mathrm{f}_{\mathrm{p} 1}=220 \\
\mathrm{f}_{\mathrm{p} 2}=270 \\
\mathrm{f}_{\mathrm{s} 2}=280\end{array}$ & $\begin{array}{l}\mathrm{f}_{\mathrm{s} 1}=210 \\
\mathrm{f}_{\mathrm{p} 1}=220 \\
\mathrm{f}_{\mathrm{p} 2}=270 \\
\mathrm{f}_{\mathrm{s} 2}=280\end{array}$ & $163 \& 0$ & 80 \\
\hline
\end{tabular}

The proposed filter bank frequency response and its output response are plotted as shown in Figure 5 and Figure 6 respectively for the input signal band of frequencies from $410 \mathrm{~Hz}$ to 460 Hz. As a result, the first band pass filter stage only exhibited response with an improvement in specifications like high selectivity, peak response, better stopband attenuation, and quality spectral output as compared to the methods (3)(4)(5). The similar advantages are arrived in the response for $2^{\text {nd }}, 3^{\text {rd }}$ and $4^{\text {th }}$ stage bandpass filters, as shown in Figure 7, Figure 8 and Figure 9 respectively, for the input signal generated at frequencies between $480 \mathrm{~Hz}-530 \mathrm{~Hz}, 550 \mathrm{~Hz}-$ $600 \mathrm{~Hz}$ and $620 \mathrm{~Hz}-670 \mathrm{~Hz}$ respectively.

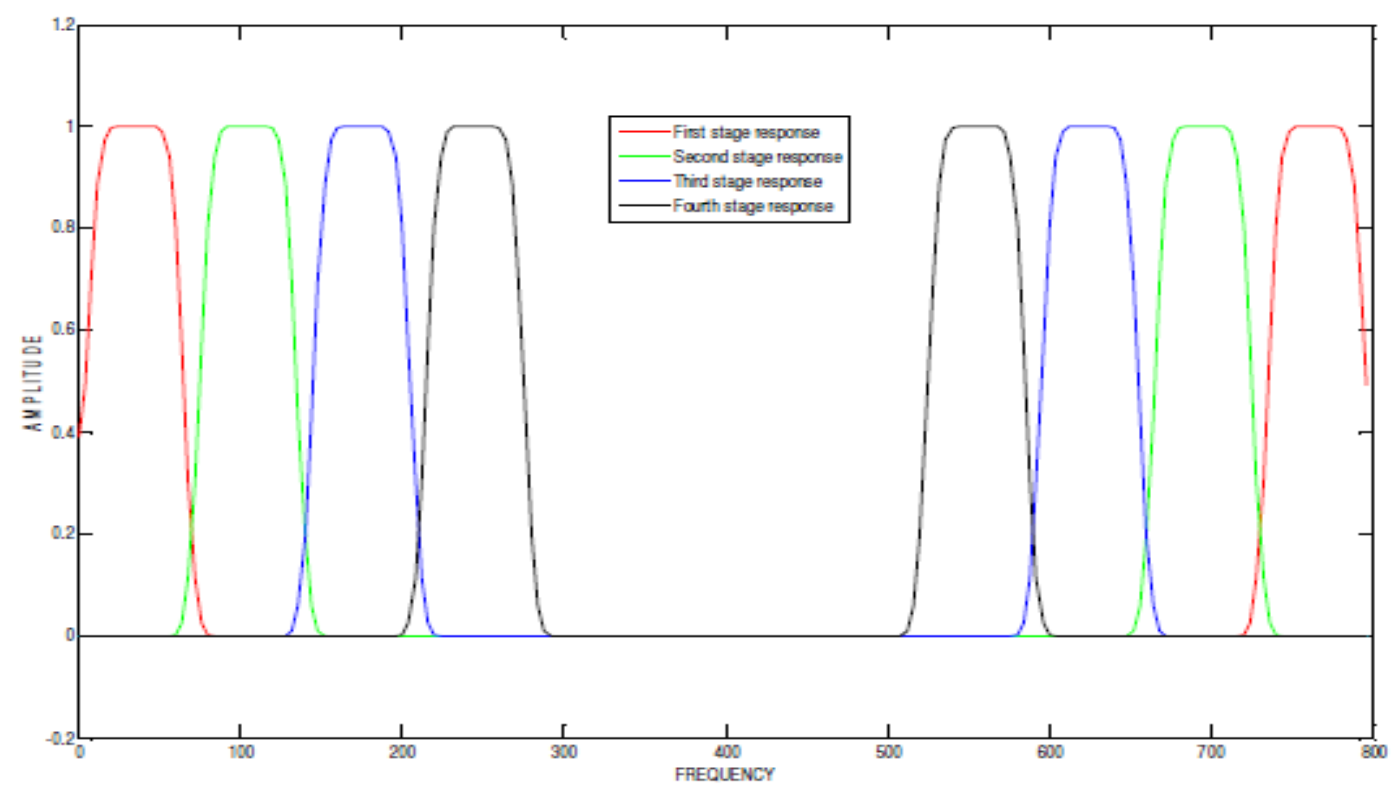

Figure 5. Frequency response of bandpass filter bank of proposed method (Using Modified Kaiser window) 
Signal \& Image Processing : An International Journal (SIPIJ) Vol.3, No.5, October 2012

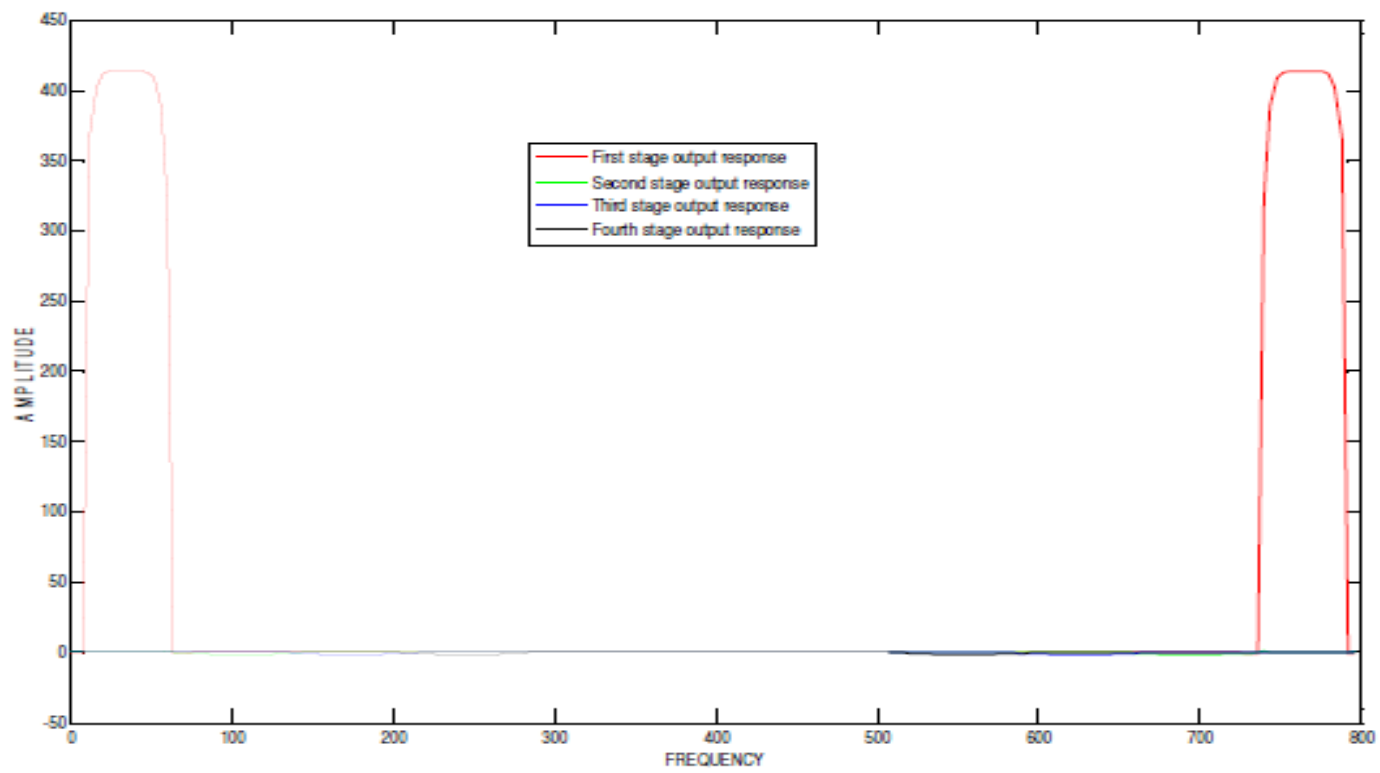

Figure 6. Output response of proposed method of filter bank for the input signal band of frequencies from $410 \mathrm{~Hz}$ to $460 \mathrm{~Hz}$ (pertaining to first stage)

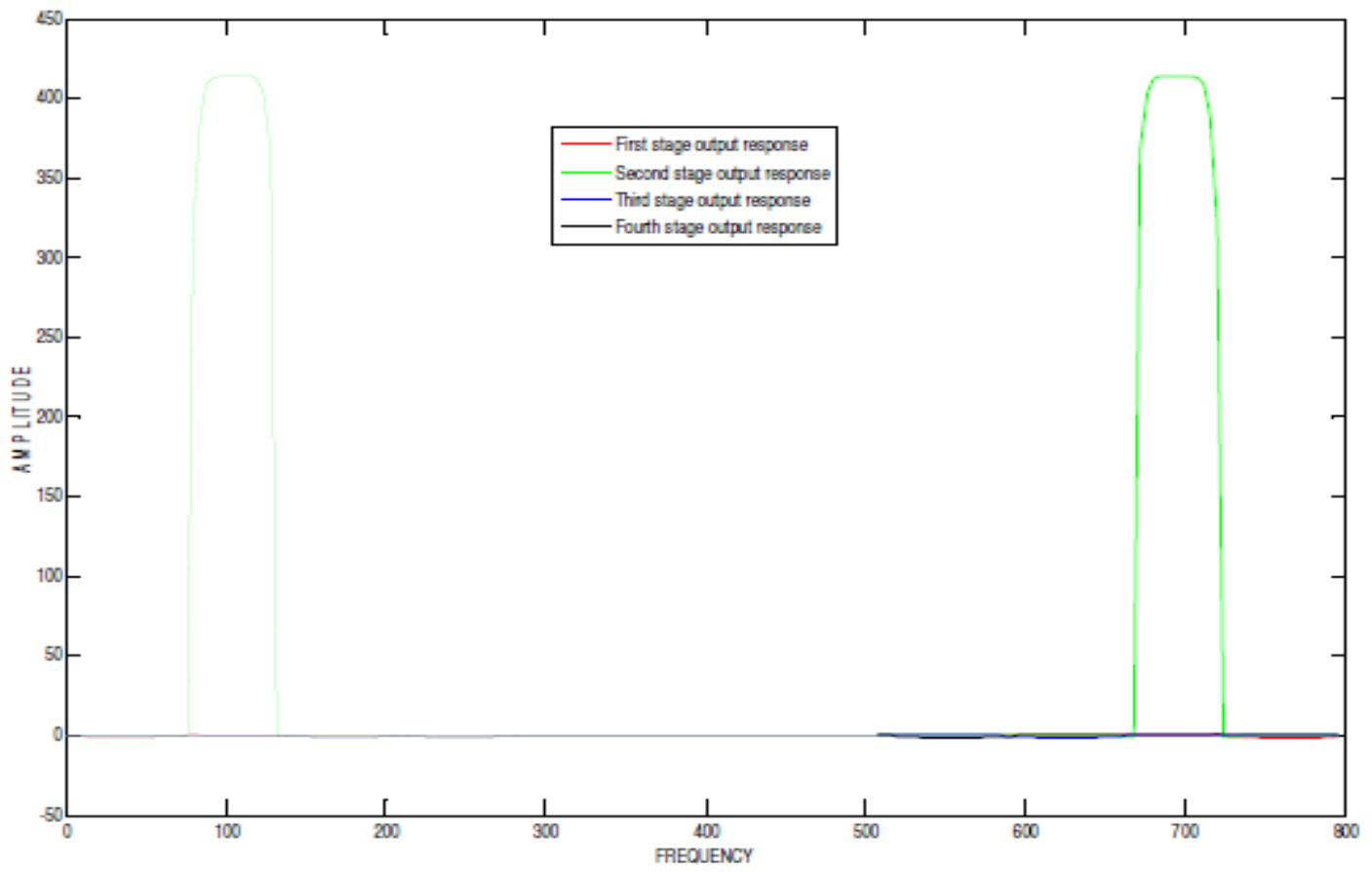

Figure 7. Output response of proposed method of filter bank for the input signal band of frequencies from $480 \mathrm{~Hz}$ to $530 \mathrm{~Hz}$ (pertaining to second stage) 
Signal \& Image Processing : An International Journal (SIPIJ) Vol.3, No.5, October 2012

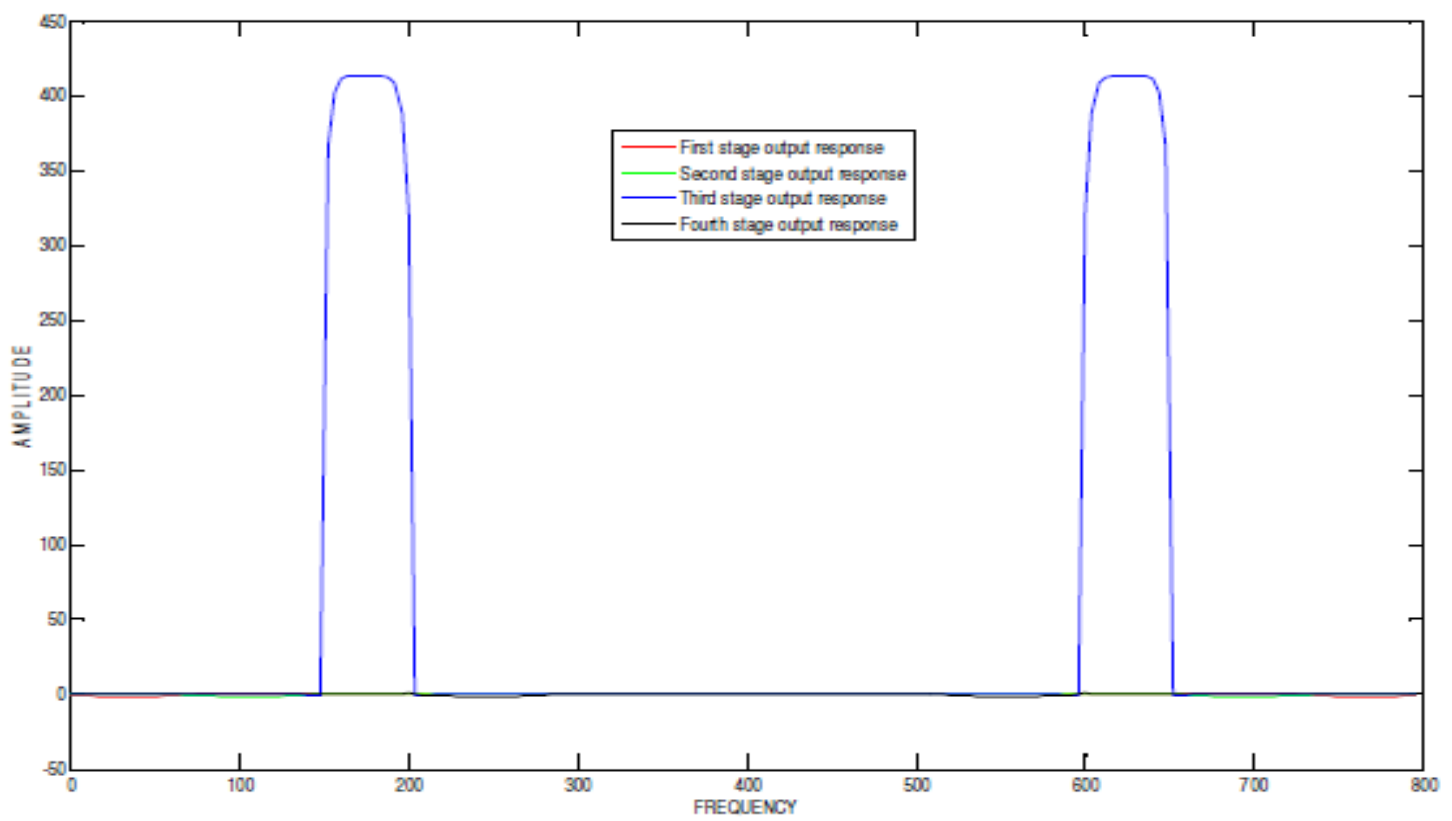

Figure 8. Output response of proposed method of filter bank for the input signal band of frequencies from $550 \mathrm{~Hz}$ to $600 \mathrm{~Hz}$ (pertaining to third stage)

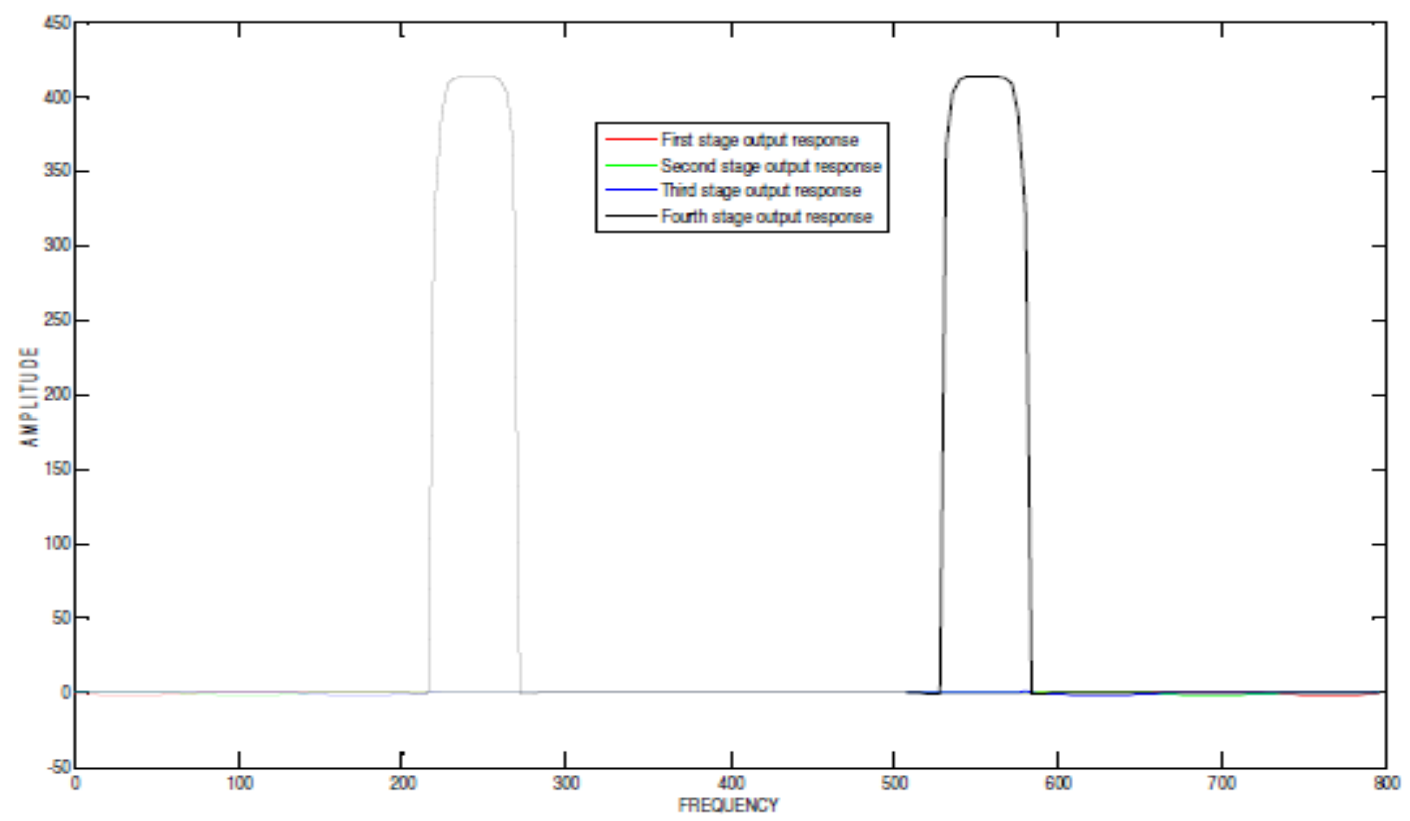

Figure 9. Output response of proposed method of filter bank for the input signal band of frequencies from $620 \mathrm{~Hz}$ to $670 \mathrm{~Hz}$ (pertaining to fourth stage) 
Signal \& Image Processing : An International Journal (SIPIJ) Vol.3, No.5, October 2012

\section{Calculation of Computational Complexity}

The computational complexity is also utmost required form of concern for designing a particular method of spectral analysis because reduction of computational complexity greatly minimizes the hardware complexity besides increasing the system accuracy. Computational efficiency is carried out by calculating the number of computations required. The number of multiplications and additions for individual stage and subsequent computations required for number of stages are calculated. Assuming the number of original input samples, decimated input samples and the filter order to be ' $\mathrm{N} 1$ ', ' $\mathrm{M}$ ' and ' $\mathrm{N}$ ', the calculation of numbers of computations required for the proposed method are arrived by the following equations.

The number of multiplications required for heterodyning operation $=(\mathrm{N} 1+\mathrm{N} 1)$.

The number of additions required for arriving Net input samples $=(\mathrm{M}+\mathrm{M})$.

The number multiplications required for arriving Net input samples $=\mathrm{M}$.

The number of multiplications required for obtaining input signal frequency response

$=(\mathrm{K})(\mathrm{M})$.

Where ' $\mathrm{K}$ ' is number of frequency points in the frequency response.

The number of additions required for obtaining input signal frequency response $=(K)(M-1)$.

The number of multiplications required for obtaining the frequency response of single band pass filter $=(\mathrm{K})\left(\mathrm{N}^{\prime}\right)$.

The number of additions required for obtaining the frequency response of single band pass filter $=(\mathrm{K})\left(\mathrm{N}^{\prime}-1\right)$.

The number of multiplications required for obtaining the output response $=\mathrm{K}$.

As per above equations, the computations required are calculated subsequently for existing and proposed methods. The number of computations required is based on number of input samples, filter order and number of frequency points at output. In addition, the quality of response is dependent upon the selection of number of input samples and thus for this reason, the number of

input samples is taken as half of the sampling frequency so that the maximum quality in the response is achieved. More over, the number of computations required is reduced, when obtaining the response at reduced sampling frequency. Thus, the number of input samples are arrived as $\mathrm{N} 1=700$ and $\mathrm{M}=400$ for existing and proposed methods respectively. For existing method, the number of multiplications and additions required for single stage response are 196800 and 196200 respectively. Similarly, for the proposed method, the number of multiplications and additions required are 114000 and 113000 respectively.

As calculating for four stages in this example, the number of multiplications and additions required for existing method are 787200 and 784200 respectively. But for the proposed method the multiplications and additions are arrived to be 452400 and 449600 only.

As the computational complexity is directly related to the design parameters such as number of input samples, sampling frequency and filter order, the computations required became lesser, because, the proposed method of filter bank design is done at minimum possible values of these parameters by virtue of techniques presented in this paper. These techniques are implemented and results of simulation are successfully verified using MATLAB - 7.01. 
Signal \& Image Processing : An International Journal (SIPIJ) Vol.3, No.5, October 2012

\section{CONCLUSIONS}

With the origin of new design techniques such as Modified Kaiser window and a Novel approach in the proposed method, the frequency response and the output response of digital bandpass filter bank are simulated and comparison is drawn with existing methods in respect to Filter output specifications, Spectral response and Computational complexity. The over all performance of the Digital filter bank is improved in respect of the parameters such as selectivity, stopband attenuation, peak response and output quality when compared with the existing methods as per the results published in figures and tables. These merits of filter bank analysis are able to draw advantages in compression techniques as of (9)(10) and hearing loss compensation to improve the quality of output especially in digital hearing aid applications. In addition, because of possessing less side lobes and prescribed vanishing moments adjacent to the passband, the proposed method of filter bank is moderately better supportive for effective usage at vestigial side band modulated sequences and hence the proposed method of filter bank is better suitable in Multicarrier applications when compared with existing method (11). More over, the proposed method has become useful in deriving better gain in order to work extremely well with image coding rather than existing method (12).

\section{REFERENCES}

[1] R.E. Crochiere \& I.R. Rabiner, (1983) "Multirate Digital Signal Processing", Prentice-Hall Inc..

[2] Douglas F. Elliot, (1987) "A Hand book of Digital Signal Processing”, Academic press.

[3] Robert W Bauml \& Wolfgang sorgel, (2008) "Uniform polyphase filter banks for use in hearing aids: Design and Constraints", 16th European Signal Processing Conference (EUSIPCO-2008).

[4] Aditya Goel, (2007) "Design of multichannel filter banks for subband coding of audio signals for multirate signal processing techniques", SPIE publications.

[5] Ricky Setiawan, Victor Putra Lesmana \&Bah-Hwee-Gwee, (2005) "Design and Implementation of a low Power FIR filter bank", Journal of The institution of Engineers, Singapore, Vol. 45, Issue 5.

[6] Jovanovic-Dolecek G, (2002) "Multirate Systems: Design and Application”, Idea Group Publishers.

[7] Robert Brennum \& Todd Schneider, (1998) "A flexible filter bank structure for Extensive signal manipulations in Digital hearing aids", O-7803-4455-3/98/5 10:00(c),IEEE.

[8] David J. Defatta, Joseph C. Lucas \& William S. Hodgkiss, "Digital Signal Processing: A System Design Approach", John Wiley and Sons.

[9] T. Schmeider \& R.L. Brennan, (1997) "A Multichannel Compression Strategy for a Digital hearing Aid", proc, IC ASSP-97, Munich Germany, pp. 411-415.

[10] D.Y. Pan, (1995) "A Tutorial on MPEG Audio Compression”, IEEE Multimedia Magazine Summer, pp. 60-74.

[11] Behrouz Farhang - Boroujeny \& Chung Him (George) Yuen, (2010) "Cosine Modulated and Offset QAM Filter bank Multicarrier techniques: A Continuous - Time Prospect", EURASIP Journal on Advances in Signal Processing Volume 2010, Article ID 165654.

[12] Adams, M.D. \& Xu, D, (2010) "Optimal design of high performance seperable wavelet filter banks for image coding" of Elsevier journal article, vol.90, ISSN 0165-1684. 
Signal \& Image Processing : An International Journal (SIPIJ) Vol.3, No.5, October 2012

\section{AUTHORS}

G. Hemanja is presently working as a Lecturer in ECE Department in S.V. Govt. polytechnic, Tirupati, Andhra Pradesh, India. He received his M.Tech. degree in Electronic Instrumentation and Control Systems from Sri Venkateswara University, Tirupati, Andhra Pradesh, India. Currently he is pursuing Ph.D degree in Digital Signal Processing at J.N.T. University, Kakinada, Andhra Pradesh, India. He teaches undergraduates and diploma courses, especially in Signals and systems. His research interest includes Digital signal processing and Digital spectral analysis.

Dr. K. Satya Prasad is currently working as a Professor in ECE department and presently working as Rector, J.N.T.University, Kakinada, Andhra Pradesh, India. He received his M.E. degree from Guindy College of Engineering, Chennai, India. $\mathrm{He}$ received his Ph.D degree from IIT, Madras. He teaches undergraduates and M.Tech. courses in Signals and systems, Digital Signal processing, Communications and Radar. His research interest includes Digital signal processing.

Dr. P.Venkata Subbaiah is currently working as Principal, Amrita Sai Institute of Science and Technology, Paritala, Krishna Dt., Andhra Pradesh, India. He has worked as Professor and Head of Department in V.R. Siddhartha Engineering college, Vijayawada, Andhra Pradesh, India. He received his M.E. in Control Systems from College of Engineering, Andhra University, Andhra Pradesh, India. He received his Ph.D degree from J.N.T. University, Hyderabad, Andhra Pradesh, India. He teaches under graduates and M.Tech courses in Communications, Digital Electronics, Microprocessors and Microwave Antennas. His research interest includes Microwave Antennas and Communications.
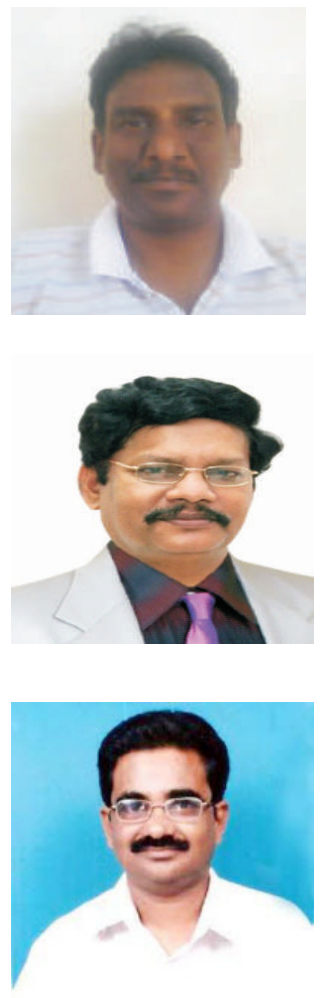